\title{
PELATIHAN JARINGAN UNTUK MENINGKATKAN JIWA KEWIRAUSAHAAN SISWA SMK \\ (IbM)
}

\author{
Akim Manaor Hara Pardede ${ }^{1}$, Novriyenni ${ }^{2}$ \\ 1. ${ }^{2}$ STMIK KAPUTAMA,Binjai \\ *akimmhp@live.com
}

\begin{abstract}
Abstrak
Jurusan bidang informatika mencakup Teknik Komputer Jaringan, Audio Visual, Design Grafis, Teknik Informatika, dll terus meningkat baik tingkat sekolah menengah maupun tingkat perguruan tinggi. Jumlah pengangguran terbesar pada kabupaten Langkat saat ini adalah tamatan SMA/SMK/SMA, hal ini terkait dengan semakin tinggiya tingkat pendidikan masyarakat, yang umumnya telah tamat SLTA melanjut ke perguruan tinggi. Banyaknya peminat jurusan bidang informatika mengakibatkan kuatnya persaingan para lulusan untuk mendapatkan pekerjaan, sehingga perlu ada upaya penanggulangan untuk meningkatkan skill siswa-siswi dan lulusan jurusan bidang informatika agar tidak semata-mata ingin mencari perkerjaan tetapi mampu membuka lapangan kerja. STMIK Kaputama merupakan perguruan tinggi pertama dalam bidang informatika di Kota Binjai. Kaputama merupakan singkatan dari Karya Putra Utama, sesuai dengan tugas utamanya melaksanakan tridharma perguruan tinggi maka dosen STMIK Kaputama terus melakukan kegiatan pengajaran, penelitian dan pengabdian masyarakat, melihat kuatnya persaingan lulusan dan kebutuhan masyarakat Kabupaten Langkat dan sekitarnya, dosen STMIK Kaputama merasa terpanggil untuk melaksanakan pengabdian masyarakat untuk meningkatkan skill siswa SMK Swasta Esa Prakarsa dan SMK Harapan Bangsa Kuala dalam bentuk pelatihan perakitan komputer, instalasi sistem operasi dan pemasangan jaringan lokal dan internet untuk membangun jaringan warnet, perkantoran dan internet desa dalam meningkatkan kemandirian siswa. Dengan adanya pelatihan perakitan komputer, instalasi sistem operasi dan pemasangan jaringan lokal dan internet, diharapkan siswa-siswi SMK Swasta Esa Prakarsa dan SMK Swasta Harapan Bangsa Kuala dapat lebih meningkatkan skill dan jiwa wirausahaan sehingga mereka mampu berwirausaha sekaligus membuka lapangan kerja secara khusus untuk dapat menerima perbaikan komputer dan membangun jaringan warnet, jaringan internet perkantoran dan jaringan internet masuk desa. Selain adanya jiwa wirausaha, masyarakat juga terbantu khususnya pedesaan agar percepatan informasi dan komunikasi dapat lebih meningkat.
\end{abstract}

Kata kunci: Internet, Jaringan-Komputer, Jaringan-Warnet, Jaringan-Perkantoran, Jaringan-Desa, Perakitan-Komputer, SMK-Wirausaha.

\section{PENDAHULUAN}

Berdasarkan angka hasil Sensus Penduduk tahun 2010, penduduk Kabupaten Langkat berjumlah 967.535 jiwa dengan kepadatan penduduk sebesar 154,48 jiwa per $\mathrm{km} 2$. Sedangkan laju pertumbuhan penduduk Kabupaten Langkat pada tahun 2010 dibandingkan tahun 2000 adalah sebesar 0,88 persen per tahun. Untuk tahun 2013 berdasarkan hasil proyeksi penduduk Kabupaten Langkat 978.734 jiwa.

Jumlah penduduk terbanyak terdapat di Kecamatan Stabat yaitu sebanyak 83.273 jiwa dengan kepadatan penduduk 765,03 jiwa per $\mathrm{km} 2$, sedangkan penduduk paling sedikit berada di Kecamatan Pematang Jaya sebesar 13.131 jiwa. Kecamatan Binjai merupakan 
kecamatan yang paling padat penduduknya dengan kepadatan 1.021,93 jiwa per km2 dan Kecamatan Bahorok merupakan kecamatan dengan kepadatan penduduk terkecil yaitu sebesar 36,57 jiwa per km2. Jumlah penduduk Kabupaten Langkat per jenis kelamin lebih banyak laki-laki dibandingkan penduduk perempuan. Pada tahun 2013 jumlah penduduk laki-laki sebesar 492.783 jiwa, sedangkan penduduk perempuan sebanyak 485.951 jiwa dengan rasio jenis kelamin sebesar 101,41 persen. (Sumber: http://langkatkab.bps.go.id/ dan http://migas.bisbak.com/)[1][2]

Jumlah pengangguran terbesar adalah tamatan SMA/SMK/SMA. Hal ini terkait dengan semakin tinggiya tingkat pendidikan masyarakat, yang umumnya telah tamat SLTA. Dilihat dari data ini menunjukkan bahwa tingkat pengangguran di Kabupaten Langkat dikategorikan sedang.

Pekerjaan terbesar penduduk Langkat berada di bidang pertanian. Jumlah ini mencapai 58 $61 \%$ dengan trend yang meningkat dari tahun 2009 ke tahun 2011. Hal ini sesuai dengan penduduk Langkat yang sebahagian besar berada di daerah pertanian dan perkebunan.. (Sumber: http://langkatkab.bps.go.id/ dan http://migas.bisbak.com/) [1][2] Program studi Teknik Komputer Jaringan di SMK Swasta Esa Prakarsa dan SMK Swasta Harapan Bangsa Kuala dalam proses belajar mengajar mengikuti kurikulum sesuai dengan standard pemerintah, sehingga siswa-siswi memiliki kemampuan dasar untuk design dan instalasi jaringan. Mengingat saat ini pendidikan dalam bidang ilmu komputer yang sangat berkembang pesat baik dalam tingkat sekolah menengah maupun tingkat perguruan tinggi, menjadikan tantangan bagi lulusan SMK karena banyaknya kompetitor dan kuatnya persaingan baik dari tingkat SMK maupun dari tingkat lulusan perguruan tinggi.Secara umum siswa-siswi SMK memiliki pengetahuan umum tentang arsitektur jaringan, topologi, Ip addres, Mikrotik, pengkabelan, setting miktorik, wifi. Dalam hal konfigurasi mereka hanya mampu untuk setting maupun design untuk personal. Selain kemampuan dalam teknologi jaringan komputer, siswa-siswi juga memperoleh pengetahuan dalam bidang wirausaha yang di dapat dari bangku sekolah (Pardede, 2016)[3]

Melihat kemampuan siswa-siswi dalam hal kemampuan dasar untuk membangun jaringan komputer serta pengetahuan dalam bidang wirausaha, sehingga siswa-siswi SMK Swasta Esa Prakarsa dan SMK Swasta Harapan Bangsa Kuala sangat potensial untuk dikembangkan sehingga mampu berwirausaha dalam hal membangun infrastruktur jaringan komputer dan internet, mampu membangun jaringan internet di warnet dan internet masuk desa. Mengingat sekarang ini perkembangan dunia infomasi dan komunikasi sangat pesat, tidak hanya diperkotaan tetapi juga sampai ke pedesaan.Wirausaha dalam hal penyediaan jasa pembangunan jaringan internet sangat menjanjikan.

\section{METODE PELAKSANAAN}

Untuk lebih jelasnya metode pelaksanaan pengabdian IbM yang diusulkan dapat di laksanakan dalam beberapa tahap (Faradisa, 2015)[4], yang digambarkan pada

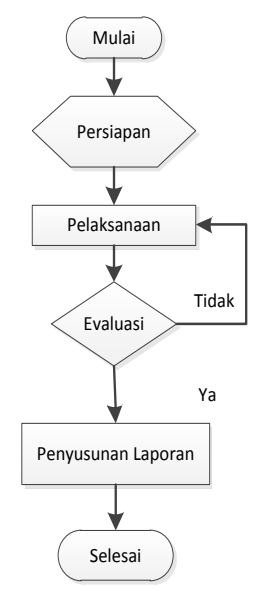

gambar 1. Flowchar Pelaksanaan dibawah ini :

Gambar 1. Flowchart Pelaksanaan 
Tahapan kegiatan pengabdian kepada masyarakat ini melalui beberapa tahapan, meliputi persiapan, pelaksanaan dan evaluasi.

Persiapan

Tahap persiapan dilakukan beberapa kegiatan, yaitu :

* Survei tempat pelaksanaan kegiatan, dalam hal ini SMK Swasta Esa Prakarsa dan SMK Swasta Harapan Bangsa Kuala.

* Wawancara dilakukan dengan Kepala Sekolah SMK Swasta Esa Prakarsa yaitu Bapak Drs. Suwito, dan Kepala Sekolah SMK Swasta Harapan Bangsa Kecamatan Kuala yaitu bapak Drs. Dahrul Sukatendel, M.Pd dengan tujuan untuk mengumpulkan data siswa dan terkait dengan keutuhan-kebutuhan pelatihan yang direncanakan

* Pembuatan modul, modul pelatihan dibagi menjadi tiga belas bagian sesuai dengan pelaksaan kegiatan

\section{Pelaksanaan Kegiatan}

Rencana pelaksanaan kegiatan dibagi menjadi beberapa tahap, yaitu (Pardede, 2016) [5] :

* Pelatihan Perakitan Komputer, Install Sistem Operasi pada client, Konfigurasi interface jaringan dan Mikrotik, Konfigurasi IP Addres

* Pelatihan Konfigurasi Gateway, Konfigurasi DNS Server, Konfigurasi NAT, Konfigurasi DHCP, Subnetting

* Pelatihan Membangun Server, Membangun Proxy, Membangun Firewall, Management Bandwidth

* Pelatihan Kofigurasi dan instalasi jaringan Warnet

* Pelatihan Konfigurasi dan instalasi jaringan perkantoran

* Pelatihan Konfigurasi dan instalasi jaringan internet desa

\section{Evaluasi}

Tahapan ini dilakukan untuk mengetahui tingkat keberhasilan kegiatan, sehingga dapat dilakukan penyempurnaan apabila ditemui kekurangan-kekurangan selama kegiatan pelatihan dilaksanakan[6][7]

Rancangan Evaluasi

Evaluasi ini bertujuan untuk mengetahui apakah terdapat peningkatan kemampuan siswa setelah dilakukannya pelatihan.

Evaluasi dilakukan dengan dua cara meliputi :

a. Pemberian Tugas :

$>$ Membuat sebuah rancangan pembangunan internet perkantoran, dengan menjelasakan gambaran jaringan dan seting ip dan internet

$>$ Membuat sebuah rancangan pembangunan internet desa, dengan menjelasakan gambaran jaringan dan seting ip dan internet

b. Ujian Praktikum

$>$ Trouble shooting komputer

$>$ Perakitan komputer dan instalasi komputer

c. Kuisioner :

Instalasi jaringan dan internet

Dimaksudkan untuk mengetahui pendapat dari peserta pelatihan mengenai kegiatan ini, sehingga dapat diketahui apakah tujuan dari kegiatan ini sudah tercapai atau belum.

d. Penyusunan Laporan

Penyusunan Laporan terbagi menjadi dua laporan kemajuan dan laporan

hasil.

\section{HASIL DAN PEMBAHASAN}

Pengabdian IbM Pelatihan Perakitan Komputer, Install Sistem Operasi Dan Pemasangan Jaringan Lokal Dan Internet Untuk Membangun Jaringan Warnet, Perkantoran Dan Internet Desa Dalam Meningkatkan Kemandirian Siswa SMK Swasta Esa Prakarsa Dan SMK Swasta Harapan Bangsa Kuala dilaksanakan sejak bulan Juni 2017 . Adapun kegiatan-kegiatan yang telah dilakukan adalah sebagai berikut :

1. Sosialisasi akan diadakannya kegiatan pengabdian IbM pada Kepala Sekolah dan siswa SMK oleh tim pengabdian

2. Peninjauan lokasi tempat pendirian tiang pipa pemancar Akses Poin pada kedua mitra pengabdian pada SMK Swasta Esa Prakarsa Dan SMK Swasta Harapan Bangsa Kuala

3. Peninjauan tempat untuk kegiatan pelatihan dalam hal pengecekan ketersediaan alat- dan perangkat yang 
dibutuhkan selama kegiatan pelatihan kepada mitra pengabdian

4. Identifikasi alat-alat yang dibutuhkan oleh mitra pengabdian

5. Mempersiapkan kegiatan pelatihan kepada mitra pengabdian tentang materi pelatihan.

6. Melaksanakan kegiatan pelatihan pengabdian : Perakitan Komputer, Install Sistem Operasi pada client, Konfigurasi interface jaringan dan Mikrotik, Konfigurasi IP Addres, Konfigurasi Gateway, Konfigurasi DNS Server, Konfigurasi NAT, Konfigurasi DHCP, Subnetting, Membangun Server, Membangun Proxy, Membangun Firewall, Management Bandwidth.

7. Publikasi kegiatan pada Koran Metro Bijai-Langkat secara cetak dan online

\section{Rencana Tahapan Berikutnya}

Adapun rencana tahapan berikutnya yang akan dilakukan adalah :

1. Memantau perkembangan siswa-siswa SMK Swasta Esa Prakarsa Dan SMK Swasta Harapan Bangsa Kuala yang telah mendapatkan pelatihan.

2. Melalui grup IbM yang telah dibuat pada group facebook diharapkan menjadi ajang komunikasi antara siswa dan tim pelaksana pengabdian, sehingga pembimbingan dan pembimbingan dapat terus dilaksanakan.

3. Melakukan pendampingan setelah dilakukan pelatihan agar sesuai dengan harapan siswa-siswa dapat mendirikan usaha atau bisnis penjualan koneksi internet pada desa.

4. Melakukan publikasi proseding dan jurnal nasional terkait dengan kegiatan Pengabdian IbM Pelatihan Perakitan Komputer, Install Sistem Operasi Dan emasangan Jaringan Lokal Dan Internet Untuk Membangun Jaringan Warnet, Perkantoran Dan Internet Desa Dalam Meningkatkan Kemandirian SMK Swasta Esa Prakarsa Dan SMK Swasta Harapan Bangsa Kuala.

5. Melakukan testing penyerapan pengetahuan yang didapat oleh siswasiswa SMK Swasta Esa Prakarsa Dan SMK Swasta Harapan Bangsa Kuala yang telah mendapatkan pelatihan, dan selanjutnya menerbitkan sertifikat pelatihan.

\section{KESIMPULAN}

Dari kegiatan pengabdian pada masyarakat ini dapat disimpulkan bahwa:

1. Pengetahuan dan pemahaman siswasiswi siswa - siswi SMK Swasta Esa Prakarsa Dan SMK Swasta Harapan Bangsa Kuala pada setiap sesi pelatihan menjadi meningkat.

2. Keinginan siswa-siswi SMK Swasta Esa Prakarsa Dan SMK Swasta Harapan Bangsa Kuala untuk berwirausaha meningkat, khususnya untuk membangun warnet milik sendiri dan menjual koneksi internet pada desa dengan memanfaatkan koneksi akses poin yang telah dipelajari pada saat pelatihan.

\section{SARAN}

Mengingat besarnya manfaat kegiatan pengabdian pada masyarakat ini, maka selanjutnya perlu:

1. Mengadakan pelatihan serupa pada siswa-siswi SMK yang berbeda serta wilayah jangkauan SMK yang lebih luas.

2. Adanya kesinambungan dan monitoring program pasca kegiatan pengabdian ini sehingga siswa-siswi SMK Swasta Esa Prakarsa Dan SMK Swasta Harapan Bangsa Kuala bdapat mempraktekan keahlian yang diperoleh selama pelatihan di wilayah desa masingmasing.

\section{UCAPAN TERIMA KASIH}

Kami menyampaikan terima kasih yang sebesar-besarnya kepada Direktorat Riset dan Pengabdian Kepada Masyakat (DRPM) Ditjen Penguatan Riset dan Pengembangan Kementerian Riset, Teknologi, dan Pendidikan Tinggi atas dukungan dana berupa hibah pengabdian Iptek bagi Masyarakat (IbM) tahun anggaran 2017. Kami juga mengucapkan terimakasih kepada mitra SMK Swasta Esa Prakarsa Dan SMK Swasta Harapan Bangsa Kuala atas pelaksanaan kegiatan pengabdian ini. 


\section{DAFTAR PUSTAKA}

Banaran Kecamatan Grogol Kabupaten Sukoharjo", Jurnal Ilmiah SINUS, Vol.7, No.2, ISSN : 1693 - 1173.

[1] http://langkatkab.bps.go.id, diakses 25 April 2016.

[2] http://migas.bisbak.com/, diakses 25 April 2016.

[3] A. M. H. Pardede and Novriyenni, "PELATIHAN JARINGAN UNTUK MEMBANGUN JARINGAN WARNET, PERKANTORAN DAN INTERNET DESA ( IbM )," in Seminar Nasional Inovasi dan Teknologi Informasi (SNITI-3), 2016, no. November, pp. 11-12.

[4] I. S. Faradisa, Y. Wahyuni, and F. T. Industri, "IBM Pelatihan dan Pendampingan Pembuatan Media Pembelajaran Interaktif untuk Guru Sekolah," Pros. Semin. Nas., pp. 270277, 2015.

[5] A. M. H. Pardede and Novriyenni, "PELATIHAN PERAKITAN KOMPUTER, INSTALL SISTEM OPERASI DAN PEMASANGAN JARINGAN LOKAL DAN INTERNET UNTUK MEMBANGUN JARINGAN WARNET, PERKANTORAN DAN INTERNET DESA DALAM MENINGKATKAN KEMANDIRIAN SISWA SMK TUNAS PELITA DAN SMK ABDI NEGARA KOTA BINJAI," TECHSIJurnal Tek. Inform., vol. 8, no. 2, pp. 18-25, 2016.

[6] S. I. Faradisa,S.I and Santi,F.W. dan Wahyuni,Y. 2015, "IbM Pelatihan Dan Pendampingan Pembuatan Media Pembelajaran Interaktif Untuk Guru Sekolah Dasar Kelurahan Tasikmadu Dan Kelurahan Tunjungsekar Kotamadya Malang", PROSIDING SEMINAR NASIONAL "RESEARCH MONTH" 2015 "Sinergi Hasil Penelitian dan Pengabdian kepada Masyarakat untuk Menumbuhkan Kapasitas Inovasi di Bidang Teknologi, Pertanian, Sosial dan Ekonomi”. ISBN:978-602-0856-43-8.

[7] S. H. Fitriasih and Utami,Y.R.W. dan Kustanto, 2009 "Pelatihan Trouble Shooting Komputer untuk Karang Taruna Desa Banaran Kelurahan 